\title{
PENGARUH BUDAYA LOKAL DALAM PILIHAN PENGGUNAAN KATA SAPAAN BERBAHASA INGGRIS
}

\author{
Ike Revita
}

\begin{abstract}
This writing is aimed at describing the phenomena of terms of address used by English Department Students when they are interacting with their lecturers in the class. Two main problems are analysed here, (1) the forms of the terms of address used by English Depratment Students and (2) the influence of $l$ terms of addreoca culture in choosing the form of the terms to address their lecturers in class interaction. Data are the terms of address used by English Department Students who are taking and already have taken Pragmatics Course. The data are takan by observational method, recording, note-taking, and interviewing technique. Pragmatic, Referential, and Translational Identity methods are used to analyze the data by applying the concept of terms of address proposed by Holmes (1992) and context Yule (1996). The result of analysis is presented descriptively. Having been analyzed, it is found that there are five forms of terms used by English Department Students to address their lecturers. They are (1) GU+GP+NP; (2) GK+NP; (3) $G U+N P$; (4) GH+NP; and (5) Bunda. The local culture that influences the choices of this terms of address are (1) raso jo pareso and (2) malu jo sopan.
\end{abstract}

\section{Pendahuluan}

Manusia merupakan makhluk sosial yang tidak bisa lepas dari manusia lain. Salah satunya terlihat dari kebutuhan untuk berinteraksi. Interaksi itu biasanya dapat dilakukan melalui bahasa. Hal ini dipertegas oleh pendapat Bloomfield (1933) bahwa manusia tidak hidup sendiri tetapi ada karena kehadiran bahasa sebagai media berekspresi dalam masyarakat.

Sebagai alat komunikasi, bahasa memiliki berbagai macam fungsi. Di antaranya adalah fungsi fatis. Fungsi fatis berarti tujuan manusia berbahasa adalah untuk membangun dan mempertahankan hubungan sosial dengan 
manusia lain (Crystal, 1980). Dengan demikian, setiap bahasa dilengkapi dengan kosa kata atau ekspresi yang digunakan untuk menyapa mitra tuturnya. Kosa kata ini disebut juga dengan kata sapaan (terms of address) (Wijana, 1991).

Untuk memilih kata sapaan ini, penutur memiliki pertimbangan tersendiri, seperti usia, jenis kelamin, status sosial, atau hubungan personalnya dengan mitra tutur. Dengan demikian, seorang penutur idealnya harus menyadari peran dan statusnya dalam interaksi sehingga mampu memilih kata sapaan yang tepat.

Bahasa Inggris sebagai salah satu bahasa yang digunakan oleh hampir seperlima bagian masyarakat di dunia juga memiliki beragam kata sapaan, seperti, Sir, Madam, Mom, Prof, atau nama diri( Garddol et al, 1996). Masingmasing sapaan ini sudah memiliki aturan atau rule tersendiri. Misalnya, Prof. dipakai untuk menyapa orang yang sudah memiliki gelar akademik Profesor atau Sir ditujukan untuk sapaan kepada orang laki-laki dewasa. Namun, fenomena yang terjadi adalah kata sapaan ini belum sepenuhnya dipakai secara tepat. Apalagi bila tuturan melibatkan peserta tutur yang berlatarbelakang budaya non-bahasa Inggris. Potensi percampuran pilihan kata sapaan dengan budaya yang paling dekat dan lekat kepada mereka sangat besar terjadi. Contohnya mahasiswa Sastra Inggris di Fakultas Ilmu Budaya Unand.

Mahasiswa Sastra Inggris FIB Unand direkomendasi, dirangsang, dan cenderung diwajibkan untuk berbahasa Inggris dalam setiap interaksi, baik antarmereka atau dengan dosen, khsususnya di dalam kelas. Artinya, dalam situasi formal, mahasiswa Sastra Inggris dikondisikan berbahasa Inggris. Namun, karena sebagian besar mereka berasal dari Minangkabau, budaya lokal Minangkabau tidak bisa terlepas dari pilihan kata sapaan yang digunakan. Demikian pula halnya bagi mereka yang non-Minangkabau. Budaya bahasa daerah atau Bahasa Indonesia cenderung melekat dalam pilihan kata sapaan yang digunakan. Contohnya dapat di lihat dalam tuturan (1) di bawah ini.

(1) $\boldsymbol{B} \boldsymbol{u}$, May I get another piece of paper.

'Bu, apakah saya boleh meminta kertas lagi?'

Sapaan ditujukan oleh seorang mahasiswa kepada seorang dosen wanita yang berusia sekitar 40 tahun. Tuturan terjadi di dalam kelas. 
Saat itu, mahasiswa ini sedang melaksanakan ujian akhir semester. Dia merasa kekurangan kertas jawaban. Oleh karena itu, dia meminta kertas tambahan dengan menggunakan sapaan Bu. Yang jelas, mahasiswa ini sudah memilih bentuk kata sapaan dalam Bahasa Indonesia. Sementara itu, dia menggunakan Bahasa Inggris dalam bertutur. Dalam Bahasa Inggris, $B u$ dapat diganti dengan Mrs. X atau Miss X. Ketika pilihan ini ditanyakan kepada mahasiswa yang bersangkutan, jawabannya adalah merasa kurang sopan kalau harus memakai Mrs. X atau Miss X. Dia menganggap sebagai orang Minangkabau, sapaan $B u$ lebih mewakili rasa hormatnya terhadap mitra tutur.

Berangkat dari realita ini, penulis tertarik untuk mengamati lebih jauh lagi mengenai pilihan kata sapaan kepada dosen yang digunakan oleh mahasiswa Sastra Inggris FIB Unand. Ada dua permasalahan yang akan diperikan, yakni (1) apa bentuk kata sapaan yang dipilih mahasiswa Sastra Inggris untuk menyapa dosennya ketika berinteraksi dalam Bahasa Inggris? dan (2) budaya lokal seperti apa yang mempengaruhi mahasiswa Sastra Inggris untuk memilih bentuk sapaan kepada dosen mereka ketika berinteraksi dalam Bahasa Inggris?

Penelitian dilakukan pada bukan April tahun 2013 terhadap mahasiswa Sastra Inggris semester VI dan telah atau sedang mengambil mata kuliah Pragmatik. Hal demikian didasari oleh sudah menguatnya kompetensi linguistik serta konteks budaya Bahasa Inggris dalam diri mereka. Data diambil dengan Discourse Completion Task (DCT). Mahasiswa diberi situasi dan konteks terkait dengan sapaan yang akan mereka pilih dan gunakan sesuai dengan konteks tersebut. Sederhananya, DCT hampir mirip dengan role play yang aksinya dituangkan melalui tulisan. Selain itu, teknik catat, rekam, dan interview juga digunakan. Hal ini diperlukan untuk mengklarifikasi alasan pemilihan bentuk sapaan. Kemudian, data dianalisis dengan metode padan pragmatik, referensial, dan translasional dengan menghubungkan pada konsep kata sapaan menurut Holmes (1992) dan konteks menurut Yule (1996). Hasil analisis dijabarkan dengan metode formal dan informal (Sudaryanto, 1993).

\section{Bahasa dan Budaya}

Language is a system of arbitrary vocal symbol which permits all people in a given culture or other people who have learned the system of that culture to communicate or to interact (Finochiaro, 1974 dalam Oktavianus dan Revita, 2013) 
Kutipan ini menjelaskan bahwa bahasa merupakan sebuah sistem, simbol bunyi, bersifat manasuka yang digunakan untuk berkomunikasi oleh masyarakat pengguna bahasa itu atau oleh orang-orang yang sudah mempelajari system bahasa tersebut. Artinya, bahasa tidak hanya digunakan oleh penutur asli, tetapi juga dapat dipelajari dan digunakan oleh orang di luar penutur asli tersebut.

Seperti halnya Bahasa Inggris, yang merupakan bahasa asing bagi masyarakat Indonesia dan Minangkabau, boleh dan dapat digunakan oleh mereka setelah sistem yang terkait dengan bahasa tersebut dipelajari. Salah satu hal yang dipelajari dalam sistem itu sudah tentu kata sapaan.

Dalam mempelajari sistem bahasa tertentu, kebudayaan pemilik bahasa itu pun mutlak dipahami. Budaya didefinisikan Wardaugh (1986) sebagai 'know-how' that a person must possess to get through the task of daily living. Budaya merupakan bagian yang harus dimiliki oleh seseorang agar dapat melakukan aktifitas sehari-harinya. Artinya, dengan memahami budaya, manusia dapat dengan mudah menjalankan hidupnya, termasuk menerapkan sistem kebahasaan yang dipelajari.

Mustahil bahasa lain dapat digunakan bila budaya masyarakat penggunanya tidak diketahui. Di sinilah letak keterkaitan antara bahasa dan budaya. Meskipun ada pendapat yang mengatakan bahwa bahasa merupakan salah satu variabel dari budaya, di sisi lain bahasa dan budaya itu saling mempengaruhi. Ini pulalah hipotesis yang dikemukakan oleh Sapir dan Whorf yang terkenal dengan Teori Relativitasnya dalam SapirWhorf Hypothesis (Sapir, 1921).

\section{Sekilas tentang Mahasiswa Jurusan Sastra Inggris dan Budaya Minangkabau}

Mahasiswa Jurusan Sastra Inggris adalah mereka yang secara resmi terdaftar di Jurusan Sastra Inggris FIB-Unand. Mahasiswa di Jurusan Sastra Inggris ini dibekali mata kuliah yang terkait dengan Bahasa Inggris dan budaya Inggris. Dalam perkuliahannya, materi disampaikan dengan menggunakan Bahasa Inggris. Meskipun demikian, untuk alasan dan pertimbangan tertentu, kadang-kadang digunakan juga Bahasa Indonesia atau bahasa daerah-Minangkabau.

Karena dikondisikan seperti di atas, mahasiswa Jurusan Sastra Inggris pun cenderung termotivasi untuk menggunakan Bahasa Inggris dalam interaksi antarmereka atau dengan dosen. Namun, ketika di luar kelas, 
kondisi ini relatif agak longgar. Banyak antarmahasiswa Sastra Inggris yang tidak berbahasa Inggris. Sebagian kecil masih tetap mempertahankan dengan keep using English totally 'berbahasa Inggris terus menerus' dan partially using English 'bercampur antara Bahasa Inggris dengan bahasa daerah atau Bahasa Indonesia'. Yang paling dominan adalah kelompok kedua ini, partially using English. Mereka melakukan percampuran kode dalam berbahasa Inggris-- Inggris-Indonesia dan Inggris-Minangkabau/ bahasa ibu mereka.

Secara umum, mahasiswa Jurusan Sastra Inggris berasal dari suku Minangkabau. Dengan demikian, dalam berbahasa, khususnya menggunakan kata sapaan, budaya Minangkabau tidak bisa mereka lepaskan.

Masyarakat Minangkabau dengan budaya Minangkabau identik dengan nan ampek 'yang empat'. Seorang Minangkabau dikatakan orang Minang jika dia tahu dengan yang empat, yakni (1) raso, (2) pareso, (3) malu, dan (4) sopan. Keempat hal ini terintegrasi dalam perilaku dan tindak tutur berbahasa (Nizar, 2004).

Revita (2010) menjabarkan raso sebagai perasaan atau keinginan yang bertempat di hati. Pareso berarti periksa atau rasionalitas yang bertempat di kepala. Hal ini sesuai dengan ungkapan raso dibao naiak, pareso dibao turun 'rasa dibawa naik, periksa dibawa turun'. Artinya, sesuatu yang diinginkan perlu diberi pertimbangan akal atau selalu dipikirkan secara matang. Sebaliknya, sesuatu yang telah jelas kerasionalannya tidak harus langsung dilaksanakan, tetapi diberi pertimbangan dengan hati yang bersifat tenggang manenggang atau tepa selira dengan sesama manusia, alam, dan lingkungan. Malu dan sopan artinya, seorang Minangkabau harus senantiasa bersikap malu dan sopan sebagai pengamalan terhadap ajaran Islam, agama yang dianut masyarakat Minangkabau.

Sehubungan dengan hal ini, Mahasiswa Sastra Inggris yang berlatar belakang budaya Minangkabau berpotensi untuk berbahasa dan memilih bentuk kata sapaan berdasarkan budaya Minangkabau, walaupun disampaikan dengan Bahasa Inggris. Dengan kata lain, di saat berbahasa Inggris, latar belakang budaya yang dipakai cenderung tetap Minangkabau, bukannya budaya Inggris.

\section{Kata Sapaan}

Kata sapaan terkait dengan suatu sistem yang menghubungkan 
bentuk kebahasaan atau elemen linguistik yang digunakan untuk menyapa orang lain. Wijana (1991) mengatakan kata sapaan merupakan sejumlah kata yang digunakan untuk menyapa seseorang.

Dalam Bahasa Inggris, ada beberapa kata yang dipilih untuk menyapa orang lain. Beberapa di antaranya adalah (1) Tittle 'gelar' baik (a) gelar umum, seperti Sir, Madam, Miss, (b) gelar professional, seperti Proffesor, Doctor, (c) gelar kekerabatan, seperti Mommy, Daddy, Aunty, dan (d) gelar hormat, seperti Mr. atau Mrs.; (2) First Name 'Nama Pertama', seperti Barrack untuk Barrack Obama; (3) Last Name 'Nama Terakhir', seperti Obama untuk Barrack Obama; atau (4) Kombinasi dari ketiga cara di atas, seperti Prof. Thomas (untuk Thomas Anthony atau Mr. Deep (untuk Henry Deep).

Selain itu ada juga orang yang menghilangkan kata sapaan itu dalam menyapa orang lain. Artinya kata sapaan bersifat $\varnothing$ (zero). Hal ini dapat dilihat dalam tuturan (2) di bawah ini.

(2) Come here, Ø!

Penutur dalam bertutur menghilangkan kata sapaan. Kata sapaan yang hilang dapat diisi dengan nama pertama Jhon atau nama terakhir Smith jika ditujukan kepada seseorang yang bernama Jhon Smith. Bentuk seperti (2) ini terjadi dapat dimotivasi oleh beberapa alasan. Misalnya, penutur lebih superior dibandingkan mitra tutur atau penutur memiliki kedekatan hubungan dengan mitra tutur.

Dari uraian di atas, penulis membagi bentuk kata sapaan dalam Bahasa Inggris menjadi dua, yakni (1) disopaque terms of address dan (2) opaque terms of address. Untuk lebih jelasnya dapat dilihat di bagan 1 berikut.

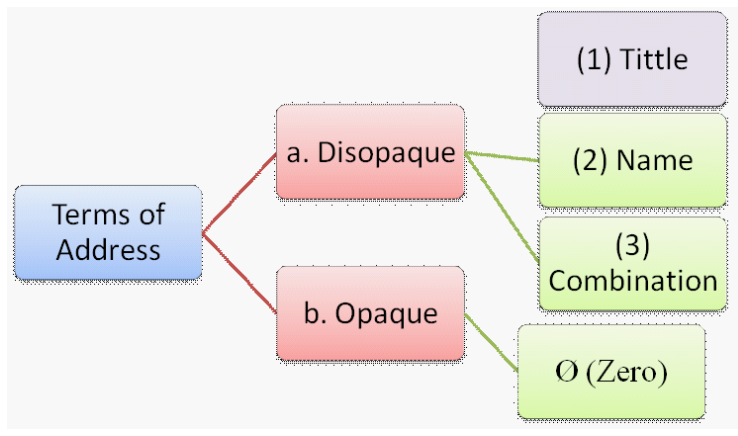

\section{Bagan 1. Bentuk Kata Sapaan dalam Bahasa Inggris}


1. Pilihan Kata Sapaan dalam Bahasa Inggris yang Digunakan Mahasiswa Sastra Inggris untuk Menyapa Dosen Mereka

Tidak satu jalan ke Roma, demikian kata pepatah. Tidak satu pilihan bentuk kata sapaan yang digunakan untuk menyapa orang lain. Begitu pula halnya dengan mahasiswa Sastra Inggris Unand yang memilih berbagai macam bentuk kata sapaan untuk menyapa dosen mereka di dalam kelas. Pilihan-pilihan itu adalah:

\section{A. $\mathbf{G U}+\mathbf{G P}+\mathbf{N P}$}

Yang dimaksud dengan GU adalah gelar umum, GP adalah Gelar Profesional, dan NP adalah Nama Pertama. Sapaan berupa kombinasi tiga bentuk sekaligus digunakan untuk menyapa dosen yang sudah bergelar professor. Sapaan seperti ini relatif biasa dilakukan oleh mahasiswa Sastra Inggris. Misalnya seperti yang terlihat dalam tuturan (3) - (4) di bawah ini.

(3) Thank you, Bapak Prof. A.

'Terimakasih, Bapak Prof. A.'

(4) Bapak Prof. B, Thank you for the chance given to us

'Bapak Prof. B, Terimakasih atas kesempatan yang diberikan kepada kami’.

Tuturan (3) - (4) terjadi dalam sebuah kelas. Saat itu penutur yang merupakan moderator akan membuka kegiatan seminar tim kelompoknya. Sebelum dia memberi kesempatan kepada anggota tim untuk memaparkan materinya, penutur mengucapkan terimakasih terlebih dulu kepada dosen pengampu mata kuliah tersebut. Dosen pengampuitu adalah seseorang yang sudah bergelar profesor.

Dalam tuturan (3) - (4), penutur tidak hanya mengkombinasikan tiga bentuk kata sapaan sekaligus, tetapi juga mencampurkan kata sapaan dalam Bahasa Indonesia Pak dan Bahasa Inggris Prof. A. Dalam konteks budaya Bahasa Inggris, tanpa menggunakan Pak, sapaan Prof. $A$ atau Prof. $B$ sudah dianggap sopan. Bagi mereka, dengan memanggil gelar profesi sudah dinilai sopan. Hanya penutur memilih bentuk seperti ini karena dia merasa tidak sopan jika harus menghilangkan kata sapaan kehormatan Pak kepada dosen yang dihormatinya.

Alasan dan pertimbangan kehormatan, membuat penutur 
memilih kombinasi bentuk kata sapaan yang cukup komplit. Bahkan, kombinasi juga terjadi di bahasa. Namun, bentuk dan pilihan seperti ini tidak terjadi bila dosennya adalah seseorang yang bergelar doktor atau master. Kalaupun ada yang menyapa dengan Ibu Doktor X, misalnya, itu tidak lebih menyebutkan nama gelar saja. Apalagi, sangat jarang seseorang yang bergelar akademik setingkat doktor disapa dengan Dok, seperti halnya profesor dengan Prof, kecuali Dok untuk sapaan kepada profesi dokter. Yang jelas, perlu dilakukan penelitian lebih jauh lagi untuk memerikan fenomena ini.

\section{B. $\mathbf{G K}+\mathbf{N P}$}

GK adalah Gelar Kekerabatan dan NP adalah Nama Pertama. Kombinasi GK + NP cenderung cukup sering dipilih oleh mahasiswa Sastra Inggris dalam menyapa dosen mereka. Contohnya dapat dilihat pada tuturan (5) - (6) berikut.

(5) Mom I, may we ask you a question?

'Ibu I, boleh saya menanyakan sesuatu?'

(6) Could you explain it again, Mom J?

'Bisakah Ibu menjelaskannya lagi, Bu J?'

Kedua tuturan (5) dan (6) dituturkan oleh mahasiswa Sastra Inggris yang ingin agar materi yang belum mereka pahami diulas lagi oleh dosennya. Untuk itu, mereka meminta dengan memilih bentuk kata sapaan Mom I dan Mom J. Kedua bentuk sapaan ini kalau diterjemahkan dalam Bahasa Indonesia adalah Ibu I dan Ibu J. Bahasa Inggris tidak lazim menggabungkan kata sapaan Mom dengan nama. Penggunaan Mom saja sudah cukup karena sapaan mom ini biasanya digunakan untuk peserta tutur yang hubungannya sangat dekat. Dalam konteks ini, si mahasiswa merasa tidak yakin dan khawatir dianggap kurang sopan kalau hanya menggunakan sapaan mom tanpa diikuti oleh nama.

\section{C. $\mathbf{G U}+\mathbf{N P}$}

GU merupakan Gelar Umum dan NP adalah Nama Pertama. Kombinasi GU + NP relative terbatas dipakai mahasiswa. Contohnya adalah sebagaimana yang tergambar di tuturan (7). Dalam tuturan (7), mahasiswa ingin berdiskusi dengan dosen mereka. Untuk itu mereka mengatakan: 
(7) Miss $\boldsymbol{X}$, do you have time? We need to discuss with you.

'Ibu X, Ibu punya waktu? Kami ingin berdiskusi dengan Ibu.'

Jika diterjemahkan secara literal, kata sapaan Miss $X$ bermakna 'Nona $X^{\prime}$. Namun, dalam konteks ini, tanpa mengurangi rasa hormat, mahasiswa lebih memilih kata sapaan Miss dibandingkan yang lain karena dosen tersebut relatif masih muda dan belum menikah. Mereka menganggap tidak tepat bila harus menyapa dengan Mom X.

\section{D. $\mathbf{G H}+\mathbf{N P}$}

GH adalah Gelar Kehormatan dan NP adalah Nama Pertama. Kombinasi ini sering dipakai bila sapaan ditujukan kepada dosen yang berjenis kelamin laki-laki dan bukan bergelar profesor. Contohnya seperti yang terlihat dalam tuturan (8) - (9) berikut.

(8). Mr. $\boldsymbol{Y}$, is it oke if the class begins now?

'Pak Y, apakah memungkinkan jika kelas dimulai sekarang?'

(9) We agree with that, $\boldsymbol{M r} . \boldsymbol{Z}$.

'Kami setuju dengan itu, Pak Z.'

Tuturan (8) dituturkan oleh mahasiswa yang berkeinginan agar kelas segera dimulai, sedangkan tuturan (9) merupakan tuturan menyatakan kesepahaman mahasiswa dengan tawaran yang ditawarkan dosen Z. Dalam tuturan (8) - (9), mahasiswa memilih kata sapaan Mr. + Nama Pertama. Hal ini karena mahasiswa menganggap aneh jika mereka harus menggunakan sapaan umum Sir $X$ atau Sir $Z$ kepada kedua dosen tersebut. Rasa hormat dan ketidaknyamanan memilih bentuk gelar umum membuat mahasiswa ini lebih menggunakan $M r$. X dan Mr. Z.

\section{E. Bunda}

Sapaan Bunda lazimnya ditujukan kepada kaum perempuan yang sudah menjadi ibu. Bunda berasal dari kata Ibunda yang fonem i-nya dilesapkan. (I)Bunda sejajar dengan sapaan Ayahnda, Kakanda, (A)Dinda. Sapaan yang berakhiran -nda ini merefleksikan kedekatan. Bahkan, ada seorang ahli, Soepomo Poedjosoedarmo, dalam diskusinya dengan penulis yang mengatakan bahwa sapaan seperti ini mengandung nilai kemanjaan. 
Dalam interaksinya dengan dosen, ada seorang mahasiswa Sastra Inggris yang menyapa dosennya dengan Bunda. Ketika diklarifikasi kepada mahasiswa yang dimaksud, sapaan tersebut hanya ditujukan kepada dosen yang juga kebetulan adalah Pembimbing Akademiknya (PA). Dia menilai bahwa PA berperan tidak hanya sebagai dosen, tetapi juga sebagai orang tua di kampus. Dengan demikian, dia beranggapan wajar bila memilih menggunakan sapaan Bunda kepada orang tuanya tersebut. Contoh penggunaan sapaan ini dapat dilihat dalam tuturan (10) dan (11).

(10) Bunda, may I get your email name? I would like to share something with you.

'Bunda, apakah saya boleh tahu nama email Bunda? Saya ingin berbagi cerita dengan Bunda.'

(11) It all depends on you, Bunda.

'Semuanya terserah Bunda.'

Menurut mahasiswa yang bersangkutan, sapaan Bunda ini tidak ada dan tidak bisa diwakili oleh terminology dalam kata sapaan Bahasa Inggris. Meskipun Bunda bisa diganti dengan My dear Mom, aspek ekspresinya tetap tidak tersampaikan.

\section{Budaya Lokal yang Mempengaruhi Pilihan Kata Sapaan oleh Mahasiswa Sastra Inggris kepada Dosen Mereka}

Setiap bahasa memiliki keunikan masing-masing dan tidak semua kosa kata dalam suatu bahasa ditemukan dalam bahasa lain. Pernyataan ini juga terkait dengan tidak adanya absolute synonym. Hal demikian terjadi karena ketika seseorang bertutur menggunakan bahasa asing atau bukan bahasa ibunya, secara tidak langsung konsep budaya bahasa ibu ini tetap melekat dalam dirinya. Akibatnya adalah terjadi ambigu bahasa.

Ambigu bahasa dimaknai sebagai bentuk kebahasaan yang salah satu pemicunya adalah ketika konsep yang ada dalam pikiran menggunakan budaya bahasa ibu, sementara wujudnya adalah bahasa bukan bahasa ibu. Dengan kata lain, tidak terjadi linearitas antara langue dan parole atau antara competence dan performance (Chomsky, 1965). Pengaruh budaya bahasa ibu inilah yang terjadi dalam pilihan bentuk sapaan yang digunakan oleh mahasiswa Sastra Inggris tatkala menyapa dosen mereka. 
Berikut adalah beberapa budaya lokal terkait dengan nan ampek sebagai dasar yang mempengaruhi mahasiswa Jurusan Sastra Inggris dalam menyapa dosen mereka.

\section{A. Budaya Raso jo Pareso}

Sebagaimana yang sudah dijelaskan di atas, raso jo pareso terkait erat dengan sikap bepikir cermat dan teliti sebelum mengatakan sesuatu. Kecermatan dan ketelitian itu berhubungan dengan pertanyaan (i) apakah bentuk kebahasaan akan menyakiti atau menyinggung perasaan orang lain? ; (ii) apakah bentuk kebahasaan dapat membuat orang lain menjadi malu?; dan Andai hal yang sama terjadi pada kita, bagaimana perasaan kita?

Pertimbangan seperti ini membuat mahasiswa Sastra Inggris memilih bentuk kata sapaan yang menggabungkan beberapa bentuk. Contohnya yang terdapat dalam tuturan (3) - 6). Dalam tuturantuturan ini, pengaruh budaya Minangkabau cukup kentara. Penutur tidak hanya menggunakan sapaan yang tumpang tindih antara gelar professional + Nama, tetapi juga mencampurkan bahasa Inggris dengan bahasa ibu.

Fenomena tidak jauh berbeda juga ditemukan dalam tuturan (5) - (6) yang penutur mengkombinasikan sapaan Mom + Nama. Bentuk sapaan seperti ini dipengaruhi oleh budaya Minangkabau Indonesia dan masyarakat Indonesia secara umum untuk menyapa orang lengkap dengan namanya, seperti Bu Tati, Bu Heni, atau Pak Riko. Kata sapaan ini jika diterjemahkan ke dalam Bahasa Inggris akan menjadi Mom Tati, Mom Heni atau Mr. Riko. Untuk sapaan Mr. Riko dapat berterima dalam Bahasa Inggris, tetapi tidak dengan Mom Tati atau Mom Heni. Yang biasa dipakai dalam Bahasa Inggris adalah Mom atau Heni/Tati saja.

\section{B. Budaya Malu jo Sopan}

Malu dan sopan berimplikasi bahwa seorang Minangkabau harus senantiasa bersikap malu dan sopan sebagai pengamalan terhadap ajaran Islam, agama yang dianut masyarakat Minangkabau. Oleh karena itu, seorang Minangkabau senantiasa berbahasa secara sopan, sesuai dengan konteks. Contohnya yang terdapat dalam tuturan (7).

Dalam tuturan (7) ini, penutur berusaha memilih bentuk sapaan yang tepat kepada dosen yang masih berusia muda. Meskipun secara 
umum dalam Bahasa Indonesia, semua dosen, tidak peduli berusia tua atau muda, sama-sama disapa dengan $B u$. Dalam Bahasa Inggris sapaan $B u$ ini diterjemahkan Madam atau Mrs.

Pertimbangan yang sama juga terlihat dalam tuturan (10) (11). Penutur memilih sapaan Bunda karena kata ini dianggap dapat mencairkan formalitas interaksi tanpa mengurangi rasa hormat kepada mitra tutur. Penutur memilih Bunda karena dosen yang disapa adalah pembimbing akademiknya-orang tuanya di kampus. Orang tua dan kampus adalah dua hal yang bertolak belakang. Yang pertama berimplikasi informal dan yang kedua formal. Ketika informal dan formal digabungkan, lahirlah wujud sapaan Bunda. Ada rasa hormat dalam sapaan Bunda karena situasinya formal, tetapi kedekatan seorang anak dengan ibunya pun tetap melekat.

\section{Penutup}

Bahasa dan budaya adalah ibarat dua sisi mata uang yang bersifat saling melengkapi. Bahasa tidak mungkin ada tanpa budaya, dan budaya pun tidak bisa berjalan tanpa adanya bahasa. Masing-masing bahasa dengan budayanya memiliki fitur distingtif yang membuat mereka tidak sama satu yang lain. Misalnya dalam kata sapaan. Setiap bahasa memiliki bentuk kata sapaan dengan penggunaannya masing-masing. Yang terjadi adalah ketika kata sapaan bahasa tertentu digunakan oleh penutur yang bukan masyarakat asli bahasa itu. Ambigu kata sapaan tidak dapat dihindari.

Mahasiswa Jurusan Sastra Inggris kebanyakan berlatar belakang budaya Minangkabau. Ketika menggunakan kata sapaan dalam Bahasa Inggris, konsep budaya Minangkabau tidak jarang masih melekat. Akibatnya, muncullah kata sapaan yang dibayangi budaya Minangkabau. Dari hasil penelitian yang dilakukan pada mahasiswa Sastra Inggris yang sedang dan telah mengambil mata kuliah Pragmatik pada bulan April tahun 2013, ditemukan beberapa bentuk kata sapaan yang digunakan untuk menyapa dosen mereka di dalam kelas. Bentuk-bentuk itu adalah (1) Gelar Umum + Gelar Profesional + Nama Pertama; (2) Gelar Kekerabatan + Nama Pertama; (3) Gelar Umum + Nama Pertama; (4) Gelar Kehormatan + Nama Pertama; dan (5) Bunda.

Nama pertama paling sering dipakai karena pengaruh budaya Minangkabau dan Indonesia secara umum yang biasanya menyapa orang dengan nama pertama, bukan nama terakhir seperti yang dilakukan 
masyarakat Inggris. Selain itu, pilihan bentuk kata sapaan dipengaruhi oleh budaya lokal (Minangkabau). Ada dua budaya lokal yang berpengaruh, yakni (1) raso jo pareso dan (2) malu jo sopan.

\section{Referensi}

Bloomfield, Leonard. 1933. Language. New York: Henry Holt

Chomsky, Noam. 1965. Aspects of the Theory of Syntax. Cambridge: The MIT Press

Crystal, David. 1980. A First Dictionary of Linguistics and Phonetics. Boulder, Colorado: Westview Press

Graddol, David, Dick Leith, and Joan Swann. 1996. English History, Diversity and Change. London and New York: Routledge

Holmes, Janet. 1992. An Introduction to Sociolinguistics. London and New York: Longman

Nizar, Hayati. 2004. Bundo Kanduang dalam Kajian Islam dan Budaya. Padang: Pusat Pengkajian Islam dan Minangkabau Sumatera Barat

Oktavianus dan Ike Revita. 2013. Kesantunan dalam Bahasa Minangkabau. Padang: Minangkabau Press

Revita, Ike. 2013. 'Local Wisdom in Speech Sequence of Minangkabau Society: An Analysis of Request from Kato Nan Ampek Perspective'. ISMIL 17. Padang: Max Planck-UBH

Revita, Ike. 2010. 'Tindak Tutur Mahasiswa kepada Dosen'. Seminar Internasional Multi-Disciplined Linguistics. Padang: Pascasarjana Unand-MLI

Sapir, Edward. 1921. Language. USA: Harcourt, Brace and Company, Inc

Sudaryanto. 1993. Metode dan Aneka Teknik Analisis Bahasa. Yogyakarta: Duta Wacana University Press

Wijana, I Dewa Putu. 1991. 'The Use of Terms of Adrees in Bahasa Indonesia'. Tidak Dipublikasi. Laporan Penlitian. Yogyakarta: Universitas Gadjah Mada

Yule, George. 1996. Pragmatics. Oxford: Oxford University Press 